\title{
Valorization of waste thermoset material as a filler in thermoplastic: mechanical properties of phenolic molding compound waste filled PP composites
}

\author{
Fabien Bernardeau ${ }^{1}$, Didier Perrin ${ }^{1}$, Anne-Sophie Caro ${ }^{1}$, Jean-Charles Benezet ${ }^{1}$ and Patrick lenny ${ }^{1}$ \\ ${ }^{1}$ C2MA, Ecole des Mines d'Alès, 6 avenue de Clavières, 30319 ALES Cedex \\ Email: Patrick.ienny@mines-ales.fr, Web Page: http://c2ma.mines-ales.fr/
}

Keywords: recycling, phenolic molding compound, particulate composite, particle size distribution, interfacial adhesion

\section{$\underline{\text { Abstract }}$}

As most thermoset material, phenolic molding compound (PMC) wastes are an environmental problem. Very few recycling solutions have been proposed so far for this type of material. A mechanical recycling method to valorize these materials is proposed in this work. It relies on the use of phenolic waste as filler in thermoplastic. Such phenolic filler can increase mechanical properties (tensile, flexural) of the matrix, and be used in substitution of traditional particulate fillers such as calcium carbonate or talc. In this study, several morphological parameters influencing the final mechanical properties of a PMC filled polypropylene micro-composite are studied, such as filler loading rate, particles size distribution of the filler, and interfacial adhesion between the filler and the matrix. Some structural parameters are also studied and linked with mechanical properties, such as dispersion of the filler and crystallinity of the matrix. Finally, the properties of PMC filled PP are compared with $\mathrm{CaCO}_{3}$ and talc filled PP.

\section{Plan}

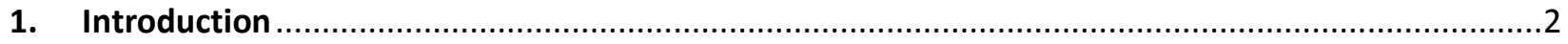

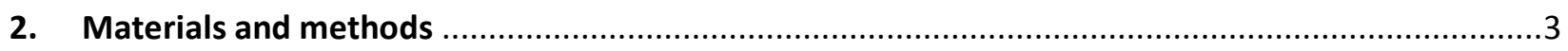

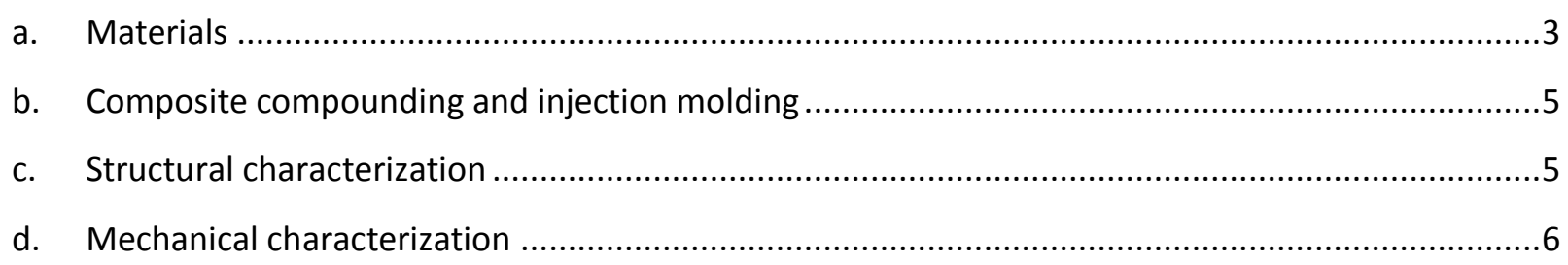

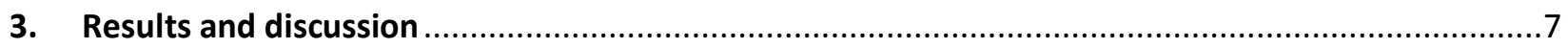

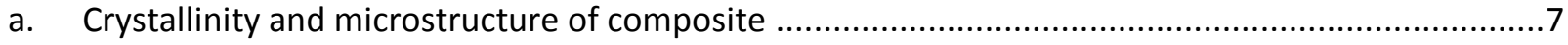
b. Mechanical properties : effect of particle size and comparison with other fillers .........................12

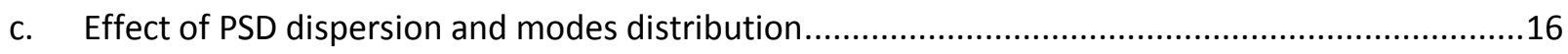

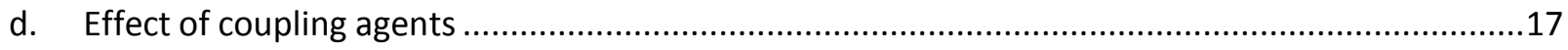

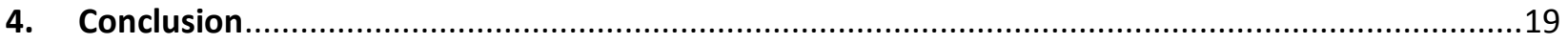

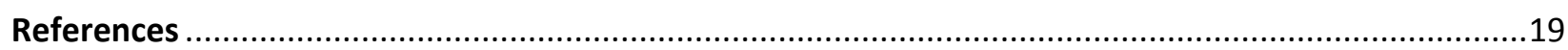




\section{Introduction}

Nowadays, recycling takes an important place in our society. Due to the increasing amount of waste produced every year, important research and industrial efforts are dedicated to the development of technic to valorize waste materials. Amongst these materials, plastics are particularly problematic. While most of them are technologically recyclable (thermoplastic material), material valorization through mechanical recycling is not directly possible or difficult for some other (thermoset and rubber material) because of their reticulate structure. Direct mechanical recycling is therefore not possible for those.

Phenolic molding compounds (PMC), also known as Bakelite ${ }^{\mathrm{TM}}$, are a particular kind of thermoset material based on phenol and formaldehyde condensation. A few research papers and patents describe valorization schemes for these materials, based on thermal recycling [1]-[4], chemical recycling [5]-[12] and mechanical recycling [13]-[18]. However, due to their complexity and the low-value of retrieved products, their industrial viability seems questionable.

For this type of thermoset plastic, mechanical recycling generally consists in comminution and incorporation in a matrix of the same or different nature (such as another thermoset, a thermoplastic, or concrete, etc.). Much of the literature on the recycling of composite material with a thermosetting matrix focuses on fiber reinforced thermoset, where the main goal is to recover the fibrous fraction (glass or carbon fiber). Such approach has been used to recycle woven glass phenolic laminates with a glass content of $80 \%$ [13]-[15]. Through a specific comminution scheme and coupling strategies of the filler with the polypropylene matrix, composites with better tensile and impact properties than the neat matrix were produced. It was shown that incorporation of phenolic prepreg (70\% glass fiber) in polypropylene increased drastically its thermo-oxidative stability and its mechanical properties after accelerated aging [18].

The mechanical recycling of non-fiber filled phenolic thermoset was investigated to a lesser extent. Incorporation of comminuted PMC into virgin phenolic resin has been proposed [17]. It led to recycled material with equal or lesser mechanical properties than virgin material. Mineral reinforced PMC has also been incorporated in polypropylene thermoplastic matrix [16]. With rather large micronized particles (median particles size superior to $420 \mu \mathrm{m}$ ), an important decrease of tensile strength with increasing fraction of filler was observed, probably linked to poor adhesion between filler and matrix.

Apart from recycling consideration, addition of uncured phenolic resin into a polypropylene matrix was also studied [19], [20]. At polypropylene processing temperature, curing of phenolic resin occurred under shearing condition. This led to the development of bi-phasic microstructure, with cured phenolic nodules of micronic or sub-micronic size within the continuous PP matrix. Good adhesion between the phenolic nodules and the matrix was achieved by using coupling agent. In these conditions, significant improvement of the mechanical properties (Young modulus, tensile strength, Izod impact strength) of the PP matrix was observed. 
The mechanical recycling approach consisting in incorporating micronized PMC in a thermoplastic matrix is developed in this work. Indeed, as previously demonstrated, very few works have been done on this topic, and represent extreme cases in terms of microstructure and mechanical properties. On one hand, incorporation of very large PMC particles with no adhesion with the matrix led to degradation of the mechanical properties. On the other hand, development through reactive extrusion of very fine phenolic inclusions with good bonding with the matrix led to significant improvement of tensile and impact properties. The aim of this work is to close the gap between those two cases, and study thoroughly the relation between the microstructure and the mechanical properties of PMC filled thermoplastic microcomposites.

While $\mathrm{n}$ the literature is not abundant on PMC incorporation in thermoplastic, the topic of mineral filled plastic has been more thoroughly studied [21]-[27]. These two subjects can be related as Young modulus of PMC is much higher than for most thermoplastic, thus it could represent a rigid inclusion in a softer matrix, similar as mineral particles. In this kind of particulate composite, several parameters are known to have a major impact on the material properties. For instance, increasing filler loading leads to an increase in composite modulus, and many models have been developed to take into account this effect [24]. However, most phenomenological models do not take into account the rigidity of the filler, assuming an infinite rigidity in comparison with the matrix. While that might be true in the case of mineral fillers, this assumption cannot be made for PMC filler.

The size of the filler is also known to influence the mechanical properties of the composite, in particular its tensile strength. An increase in filler size is usually associated with a decrease in strength when there is a poor adhesion between the filler and the matrix [24]. However, few studies have been conducted on the effect of the particles size distribution of the filler, such as dispersion of the distribution and whatever is the distribution profile (monomodal or multimodal) it is monomodal or multimodal. The decrease in particle size also leads to an increase in particles surface area, which generates an higher interfacial area with the matrix in the composite, and better opportunity for bonding. Indeed, bonding can lead to improvement in mechanical properties through stress transfer [27]. Again, many models have been developed to predict the tensile properties of composite while taking into account these parameters [25]. In the case of PMC, a tensile strength of $50 \mathrm{MPa}$ is usually measured [28], which is not much more than most thermoplastics. Thus, the potential reinforcing effect through stress transfer cannot be assumed, as its high rigidity and low deformability can leads to high level of stress concentration in the filler and breaking of particles.

In this work, the properties of PMC filled PP are studied. The effect of particles size distribution, loading rate and bonding of the filler on tensile and impact properties of composites are investigated, as well as their microstructure and crystallinity. Their properties are compared with $\mathrm{CaCO}_{3}$ and talc filled PP.

\title{
2. Materials and methods
}

\author{
a. Materials
}


PMC used in this study was recovered from WEEE (Waste Electrical and Electronic Equipment) casing. They were identified via FTIR analysis and manually sorted from other plastic parts. Further analysis showed that all these PMC samples shared the same material composition, corresponding to a normalized phenolic molding compound composition (PF2A1 in ISO 800 or PF WD4OMD5 in ISO 14526-3). This corresponds to a phenol-formaldehyde resin filled with about $40 \mathrm{w} \%$ of wood floor and less than $5 \mathrm{w} \%$ of mineral component (mainly calcium oxide and silica).

\begin{tabular}{|c|c|c|c|c|c|}
\hline $\begin{array}{c}\text { PSD } \\
(\mu \mathrm{m})\end{array}$ & $\begin{array}{c}\mathrm{d} 50 \\
(\mu \mathrm{m})\end{array}$ & $\begin{array}{c}\mathrm{d} 90 \\
(\mu \mathrm{m})\end{array}$ & $\begin{array}{c}\mathrm{S}_{\text {BET }} \\
\left(\mathrm{m}^{2} / \mathrm{g}\right)\end{array}$ & $\mathrm{RD}$ \\
\hline$<400 \mu \mathrm{m}$ & 48 & 188 & 418 & 0.62 & 1.96 \\
\hline$<200 \mu \mathrm{m}$ & 27 & 104 & 200 & 0.73 & 1.66 \\
\hline$<100 \mu \mathrm{m}$ & 6 & 50 & 114 & 1.18 & 2.17 \\
\hline$<40 \mu \mathrm{m}$ & 4 & 24 & 49 & 2.04 & 1.91 \\
\hline
\end{tabular}

PMC powders with different particle size distributions were used in this study. Four top cutted Particle Size Distributions (PSD), with median particle size (d50) ranging from 24 to $188 \mu \mathrm{m}$, were used to evaluate the effect of particle size (

Table 1). They were obtained by sieving with sieves with different mesh sizes $(400 \mu \mathrm{m}, 200 \mu \mathrm{m}$, $100 \mu \mathrm{m}$ and $40 \mu \mathrm{m})$. The notation $\mathrm{dX}$ represents the particle size distribution such that $\mathrm{X} \%$ by volume of the particles are less than or equal to the said size. However, the dispersion and number of modes were not similar in each distribution (Figure 1). The range of distribution (RD), which corresponds to the dispersion of the distribution, has been calculated as $\left(d_{90}-d_{10}\right) / d_{50}$. Their specific surface area, as measured by BET method (Micromeritics TriStar II Plus, 5 pressures point method with nitrogen), ranged from 0.62 to 2.04 $\mathrm{m}^{2} / \mathrm{g}$.

\begin{tabular}{|c|c|c|c|c|c|}
\hline $\begin{array}{c}\text { PSD } \\
(\mu \mathrm{m})\end{array}$ & $\begin{array}{c}\mathrm{d} 50 \\
(\mu \mathrm{m})\end{array}$ & $\begin{array}{c}\mathrm{d} 90 \\
(\mu \mathrm{m})\end{array}$ & $\begin{array}{c}\mathrm{S}_{\mathrm{BET}} \\
\left(\mathrm{m}^{2} / \mathrm{g}\right)\end{array}$ & RD \\
\hline$<400 \mu \mathrm{m}$ & 48 & 188 & 418 & 0.62 & 1.96 \\
\hline$<200 \mu \mathrm{m}$ & 27 & 104 & 200 & 0.73 & 1.66 \\
\hline$<100 \mu \mathrm{m}$ & 6 & 50 & 114 & 1.18 & 2.17 \\
\hline$<40 \mu \mathrm{m}$ & 4 & 24 & 49 & 2.04 & 1.91 \\
\hline
\end{tabular}

Table 1 : Dimension of particles of top cutted PMC powders (measured with a Beckman Coulter LS 13320 laser diffraction particle size analyzer equipped with a Tornado Dry Powder System)

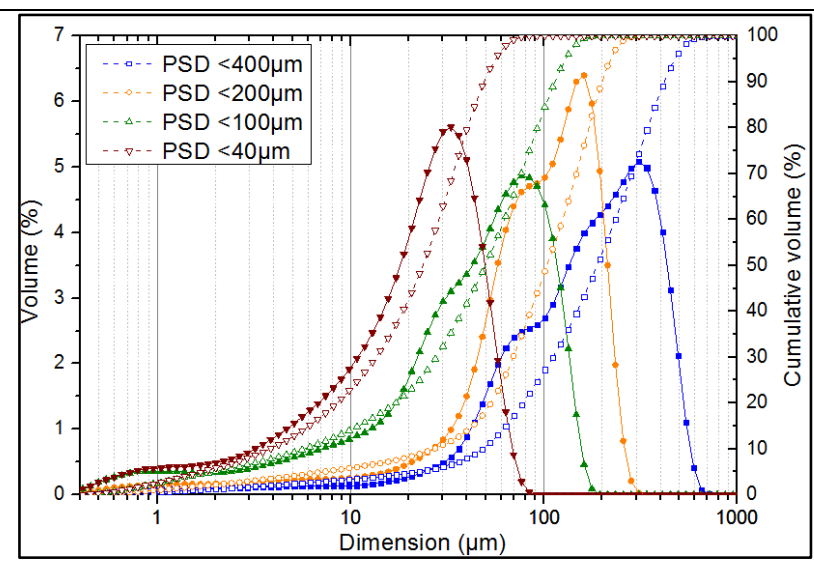

Figure 1: Dimension of particles of top cutted PMC powders (measured with a Beckman Coulter LS 13320 laser diffraction particle size analyzer equipped with a Tornado Dry Powder System)

In order to assess the effect of PSD dispersion and number of modes on mechanical properties, tailored PSD were produced. Five narrows particles size distributions (Fraction A : 0-40 $\mathrm{mm} ; \mathrm{B}: 40-80 \mu \mathrm{m}$; $C: 80-125 \mu \mathrm{m} ; \mathrm{D}: 125-160 \mu \mathrm{m} ; \mathrm{E}: 160-200 \mu \mathrm{m})$ were re-combined in order to produce tailored PSD. In particular, the effect of dispersion on a monomodal distribution was evaluated through the comparison of the fraction $C$ and a recombined PSD made of $20 \%_{w} B+60 \%_{w} C+20 \%_{w} D$ (Figure 2). A multimodal PSD made of $30 \%_{w} A+70 \%_{w} E$ was compared with pure $A$ and $E$ fractions (Figure 3 ). 


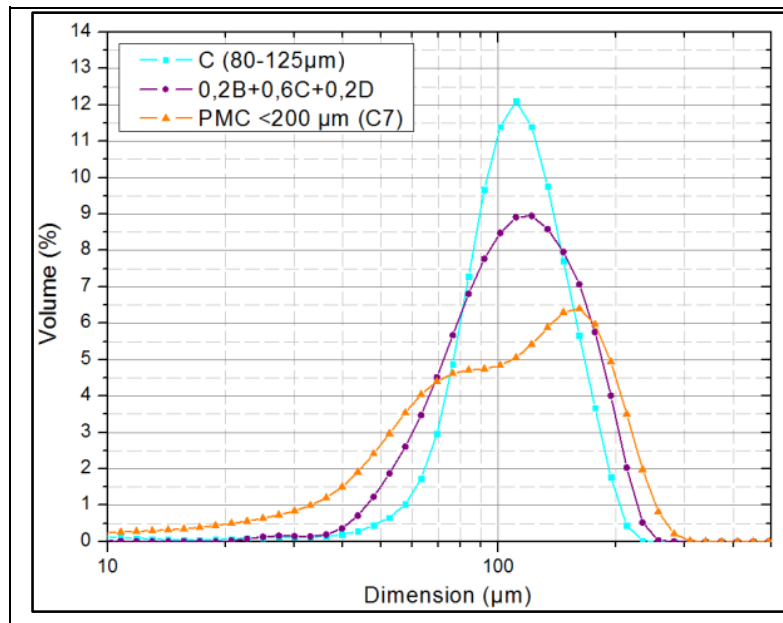

Figure 2: PSD laser (LS13320 with Tornado Dry Powder System) of a narrow $(C)$ and a broader $(0.2 B+0.6 C+0.2 D)$ distribution

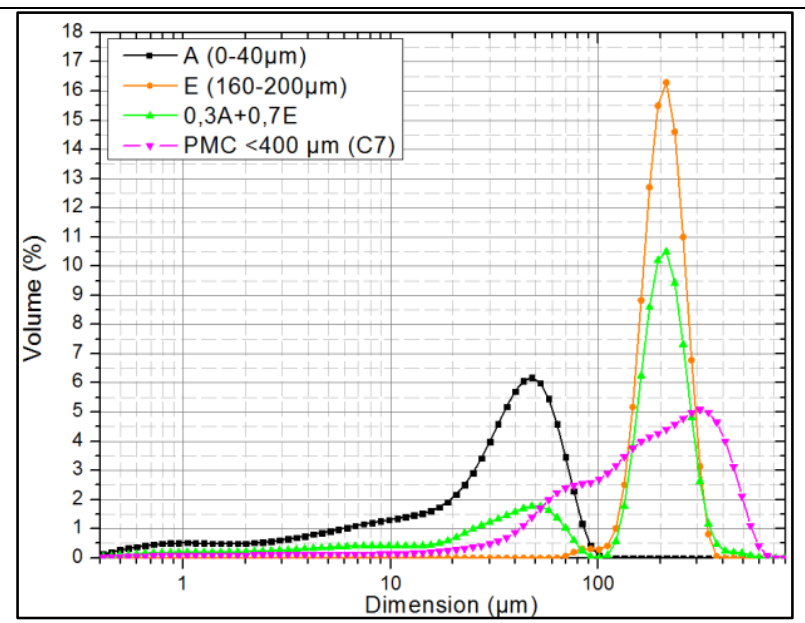

Figure 3: PSD laser (LS13320 with Tornado Dry Powder System) of two narrow distribution ( $A$ and $E$ ) and a mixture of $A$ et $E$ fractions

A Polypropylene 576P was kindly provided by Sabic. It is a PP homopolymer with narrow molecular weight distribution and a MFI of $19\left(230^{\circ} \mathrm{C}, 2.16 \mathrm{~kg}\right)$. A Polypropylene grafted with maleic anhydride (PP-gMA) Orevac CA100 from Arkema was also used in this study. In order to compare the properties of the PMC filled composites with commercially available fillers, a calcium carbonate Piketty $\left(d_{50}=6 \mu \mathrm{m}, \mathrm{S}_{\mathrm{BET}}=\right.$ $\left.0.75 \mathrm{~m}^{2} / \mathrm{g}\right)$ and a talc Luzenac A30 $\left(\mathrm{d}_{50}=18 \mu \mathrm{m}\right)$ were used. The former is a block like filler with low aspect ratio, the later has a platelet morphology.

\section{b. Composite compounding and injection molding}

Particulates composite were prepared by extrusion. All materials were dried at $80^{\circ} \mathrm{C}$ during $24 \mathrm{~h}$ in an air circulating oven prior to compounding. A Clextral BC21 co-rotating twin screw extruder was used. The temperature was set to $220^{\circ} \mathrm{C}$ at the primary feeding port, and to $210^{\circ} \mathrm{C}$ at the extrusion head. A rotation speed of $250 \mathrm{rpm}$ was used. An overall extrusion rate of $5 \mathrm{~kg} / \mathrm{h}$ was set for all composite. PMC fillers were fed in a port located in the middle of the barrel. PP-g-MA was dry-mixed with polypropylene before processing. The extruded material was cooled in a water bath and granulated. Compounds with 10 , 20 and $40 \%$ in weight of fillers were produced. Because of the difference of density of the fillers (1.4 for PMC, 2.7 for mineral fillers [23]), the volume fraction was not the same for all compounds (Table 2).

\begin{tabular}{|c|c|c|}
\hline Mass fraction of filler (PMC/ mineral) & $\begin{array}{c}\text { Volume fraction of PMC } \\
\text { filler }\end{array}$ & $\begin{array}{c}\text { Volume fraction of mineral } \\
\text { filler }\end{array}$ \\
\hline $10 \%$ & $7 \%$ & $4 \%$ \\
\hline $20 \%$ & $14 \%$ & $8 \%$ \\
\hline $40 \%$ & $30 \%$ & $18 \%$ \\
\hline
\end{tabular}

Table 2 : Corresponding mass and volume fraction of PMC and mineral fillers in compounds

After compounding, extruded materials were dried at $80^{\circ} \mathrm{C}$ during $24 \mathrm{~h}$ in an air circulating oven. The pellets were then injection molded with a Krauss Maffei KM50-T180CX. Dog bone samples (ISO $1 \mathrm{~A}$ according to ISO 527-2) were injected for mechanical testing.

\section{c. Structural characterization}


The microstructures of the composites were characterized by different means. The crystallinity was measured by differential scanning calorimetry (DSC). A Pyris Diamond apparatus (Perkin Elmer) equipped with a cooling device was used. Measurements were performed under nitrogen atmosphere to contain the impact of ageing during the test. Samples of approximately $10 \mathrm{mg}$ were sealed in a standard $50 \mathrm{ml}$ aluminum pans. Measurements were made in duplicate for each formulation. Samples were subjected to two heating steps from $20^{\circ} \mathrm{C}$ to $220^{\circ} \mathrm{C}$ at a constant rate of $10^{\circ} \mathrm{C} / \mathrm{min}$ interspersed with a cooling step. The crystallinity ratio $\chi_{c}$ was calculated from the melting enthalpy $\Delta \mathrm{H}$ of the second heating step (Equation 1).

Equation $1 \quad \chi C=\frac{\Delta H}{\Delta H_{100} \times \Phi_{P P}}$

Where $\Delta \mathrm{H}_{100 \%}$ is the melting enthalpy of $100 \%$ crystalline PP, which is considered equal to $209 \mathrm{~J} / \mathrm{g}$ [29]. $\Phi_{P P}$ is the PP weight fraction in the composite.

The dispersion, particles size distribution and morphology of the fillers in the composites was investigated by ESEM. Polished section of ISO $1 \mathrm{~A}$ samples were realized in the direction parallel to the injection flow. A FEI Quanta 200 FEG ESEM was used in electron backscattering mode. Indeed, a good contrast between fillers particles and PP matrix was observed in this mode. Pictures were taken at $x 70$

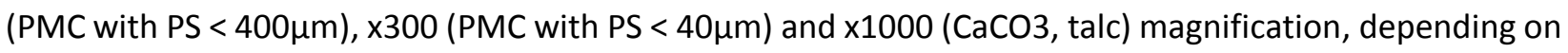
the size of the observed objects. An image analysis was performed using ImageJ software and morphological parameters have been evaluated from the pictures. Between 800 and 3000 individual particles were analyzed for each formulation. Minimum and maximum ferret diameters were measured, and the apparent aspect ratio of particles was calculated as the ratio of the later over the former. An equivalent circular diameter was calculated knowing the area of particles. An elliptic fitting was performed, and the angle between the $x$ line of the image and the major elliptic direction was also determined. Finally, the solidity was calculated by dividing the area of particles by their convex area. All frequency repartition and distribution parameters were calculated in term of surface ratio.

\section{d. Mechanical characterization}

Mechanical tests were performed on ISO $1 \mathrm{~A}$ samples. All measurements were carried out at $23^{\circ} \mathrm{C}$ $\pm 2^{\circ} \mathrm{C}$ and $50 \% \pm 5 \%$.

Tensile tests were carried out according to ISO 527 with a Zwick Z010 equipped with a $2.5 \mathrm{kN}$ load cell and a Clip-on extensometer. A pre-load of $0.8 \mathrm{MPa}$ was applied to samples priori to testing. The elastic modulus was measured at a $1 \mathrm{~mm} / \mathrm{min}$ crosshead speed between $0.05 \%$ and $0.25 \%$ of deformation (measured with the Clip-on extensometer). Ultimate properties were then measured at a crosshead speed of $50 \mathrm{~mm} / \mathrm{min}$. 5 samples were tested for each formulation. This protocol corresponds to the ISO 527-2 standard defined to analyze the mechanical properties of plastic materials.

Impact strength was measured with an impact tester Zwick 5102 according to ISO 179 standard. $80 \mathrm{~mm}$ long bar were sawn in the central part of ISO 1A samples (10 for each formulation). Samples were tested unnotched in standing position. 


\section{Results and discussion}

\section{a. Crystallinity and microstructure of composite}

The structure of the composites was first investigated. Polypropylene is a well known semicrystalline polymer, and its degree of crystallinity influences its mechanical properties (such as Young modulus). For pure polypropylene, a crystallinity of $48 \%$ was measured. The crystallinity of all composites ranges from $40 \%$ to $50 \%$ (Figure 4 ). The fillers loading rate and size seem to impact the crystallinity of the composites.

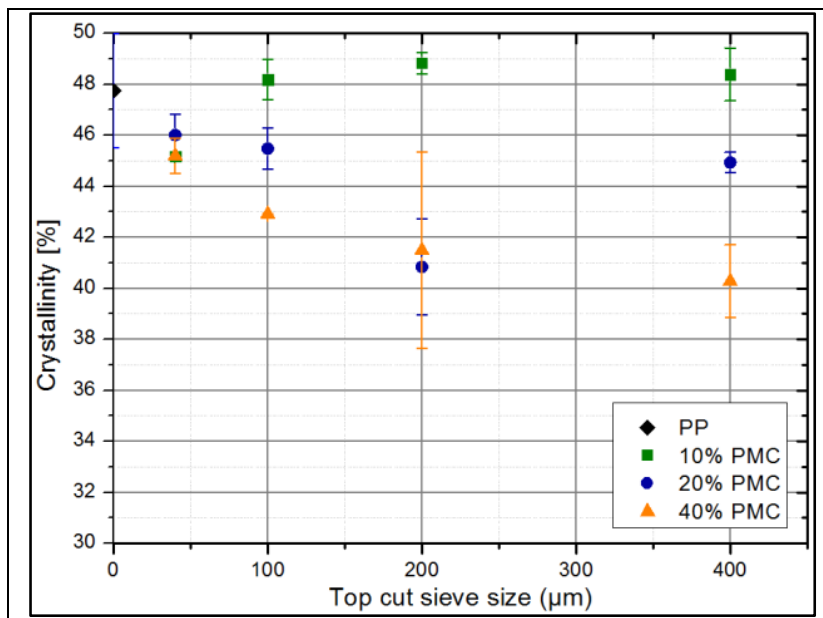

Figure 4 : Cristallinity of PMC filled polypropylene measured by DSC (10, 20 and $40 \%$ weight $)$

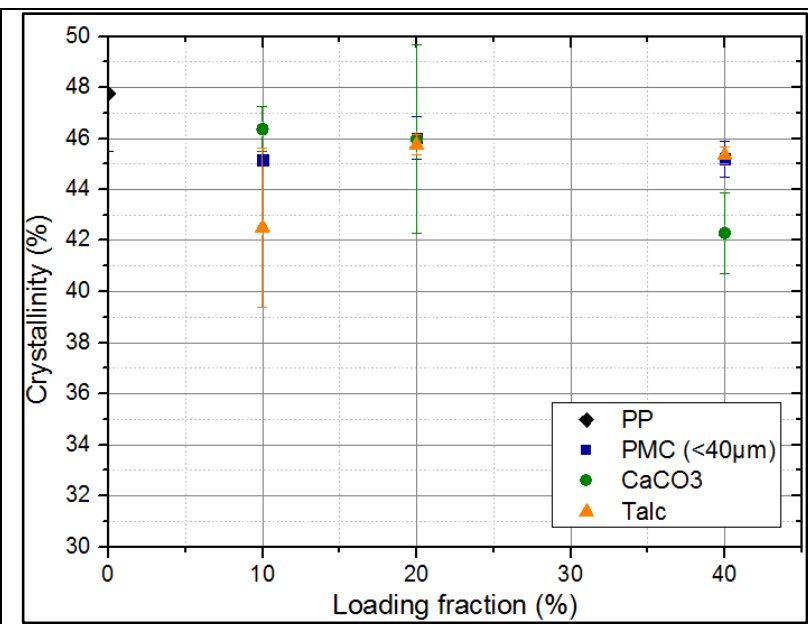

Figure 5 : Cristallinity of polypropylene filled with PMC $(<40 \mu \mathrm{m}), \mathrm{CaCO} 3$ and talc measured by DSC

At low loading $\left(10 \%_{w}\right)$, the PMC filler do not change much the crystallinity of the PP (except for $\mathrm{PMC}<40 \mu \mathrm{m}$ ). At higher volume fraction of filler, a general decrease of crystallinity is observed. This can be explained by the higher fraction of interface in the composite, where polymer chains movement are hindered by the filler and cannot form crystallite, thus stay amorphous [30]. Interestingly, almost no effect of loading fraction on crystallinity can be observed for the smaller PSD $(<40 \mu \mathrm{m})$, despite the increasing fraction of interface in the composite. This might be explained by the low interparticular distance. Indeed, it is expected that interparticular distance decreases with the size of particles. For this smaller PSD, crystal growth might be hindered by the little space available between fillers even at low loading fraction.

No clear trend can be pointed out when comparing crystallinity of PP filled with different fillers (Figure 5). All measured crystallinity values are about $45 \%$, and do not change much with loading fraction.

The nucleating effect of fillers can be observed on the crystallization temperature. It is higher for all composites than for PP (Figure 6). General trends can be identified. First, crystallization temperature increases with increasing loading fraction of fillers. It can be related to higher nucleating sites density. Crystallization temperature also decreases with increasing size of filler up to $200 \mu \mathrm{m}$, where it tends to increase or stabilize. 


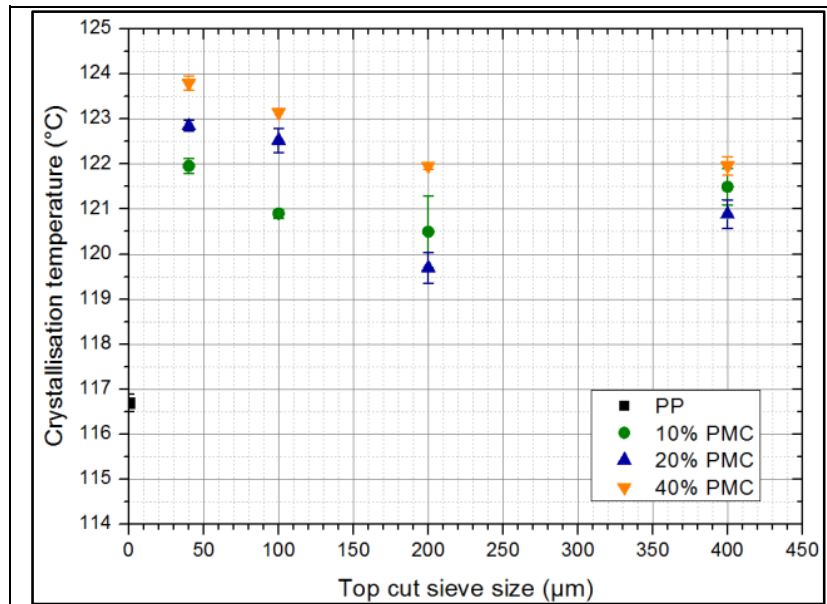

Figure 6 : Crystallisation temperature of PMC filled PP measured by DSC (10, 20 and $\left.40 \%_{\text {weight }}\right)$

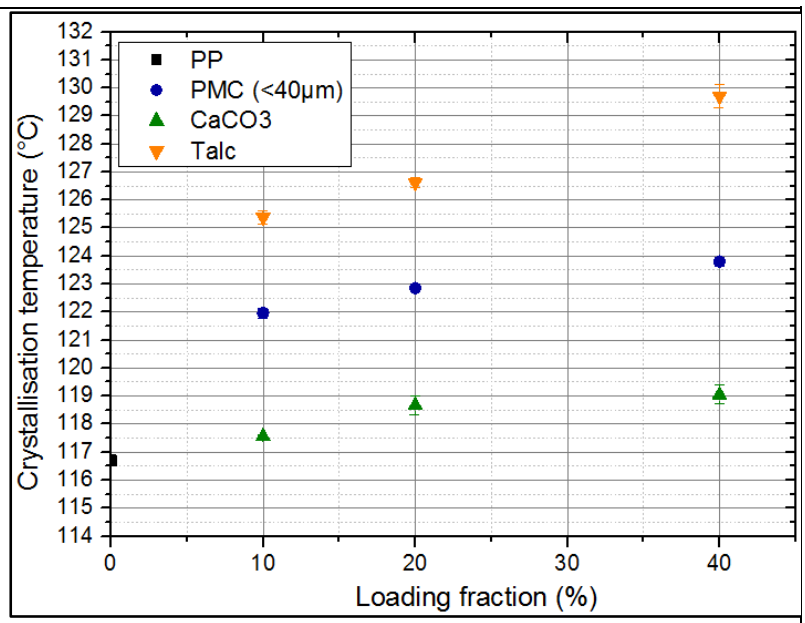

Figure 7 : Crystallisation temperature of PMC, Talc and CaCO3 filled PP measured by DSC

Therefore, smaller PSD have a better nucleating effect than larger one, until a given size. Because the PSD used in this study are quite broad and only top-cutted, it could be argued that only very fine particles fraction acts as nucleating sites. This fraction of fine particles decreases with increasing PSD median diameter (or top cut sieving mesh), leading to a lower crystallization temperature.

A higher crystallization temperature is observed for minerals filled PP than PMC filled PP (Figure 7). Again, an increase in crystallization temperature is observed with increasing filler fraction. This increase reaches $13^{\circ} \mathrm{C}$ for $40 \%$ talc filled PP. Such differences in crystallization amongst mineral fillers have already been pointed out in the literature and related to nucleating sites density on fillers surface [31]. Talc is generally found to have a higher number of nucleating site per unit surface than calcium carbonate. It was also reported that coating of $\mathrm{CaCO}_{3}$ with an organic coating (stearic acid) led to further decreases in nucleating capacity [31]. The lower crystallization temperature induced by PMC might be linked to a similar phenomenon.

It can be seen on composite polished cross section that an acceptable dispersion of all fillers is achieved through the compounding process (Figure 8, Figure 9, Figure 10 and Figure 11). 


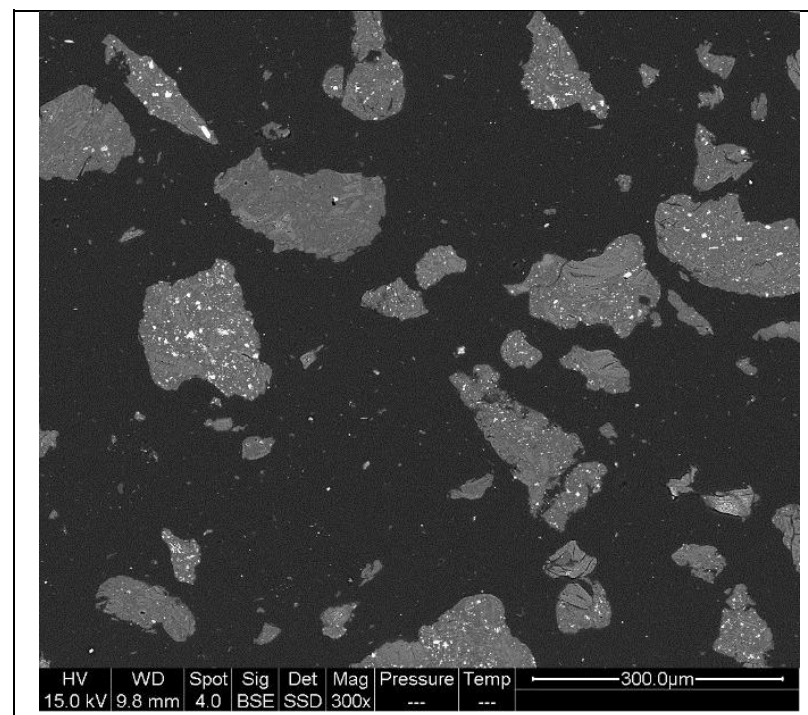

Figure 8 : ESEM observation of polished cross section of $20 \%$ PMC $(<400 \mu \mathrm{m})$ filled PP $(\times 300)$

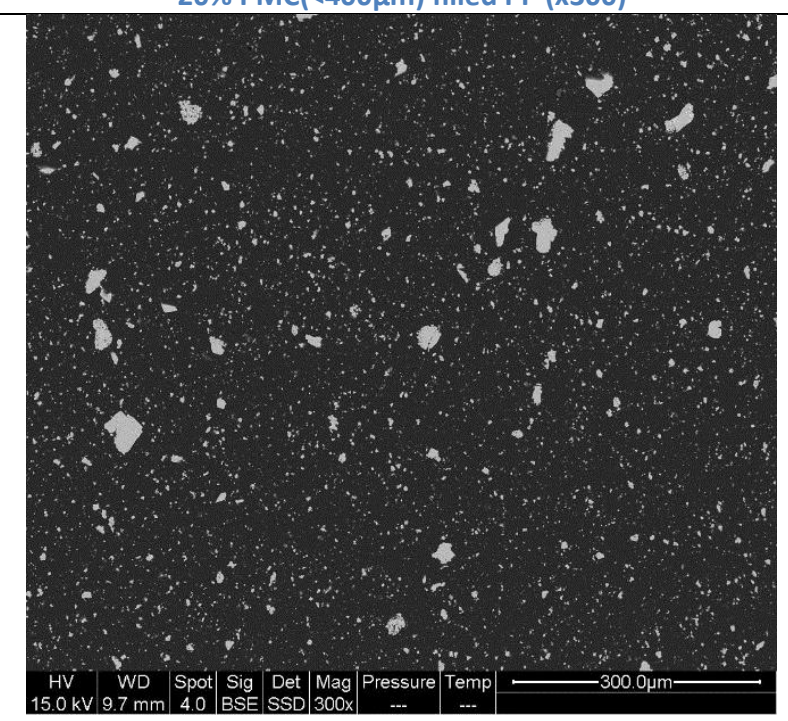

Figure 10 : ESEM observation of polished cross section of $20 \%$ CaCO3 filled PP (x300)

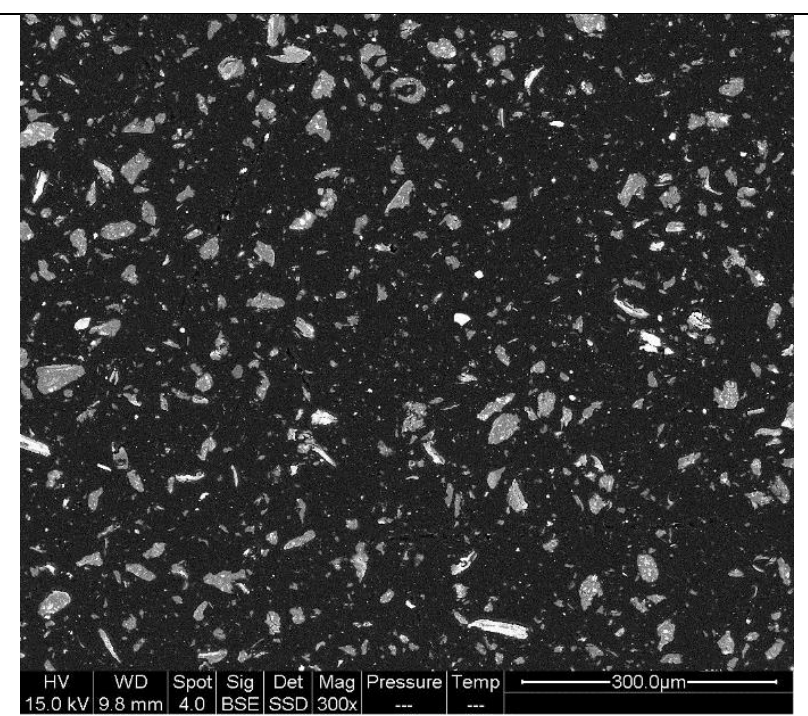

Figure 9 : ESEM observation of polished cross section of $20 \%$ PMC $(<40 \mu \mathrm{m})$ filled PP $(x 300)$

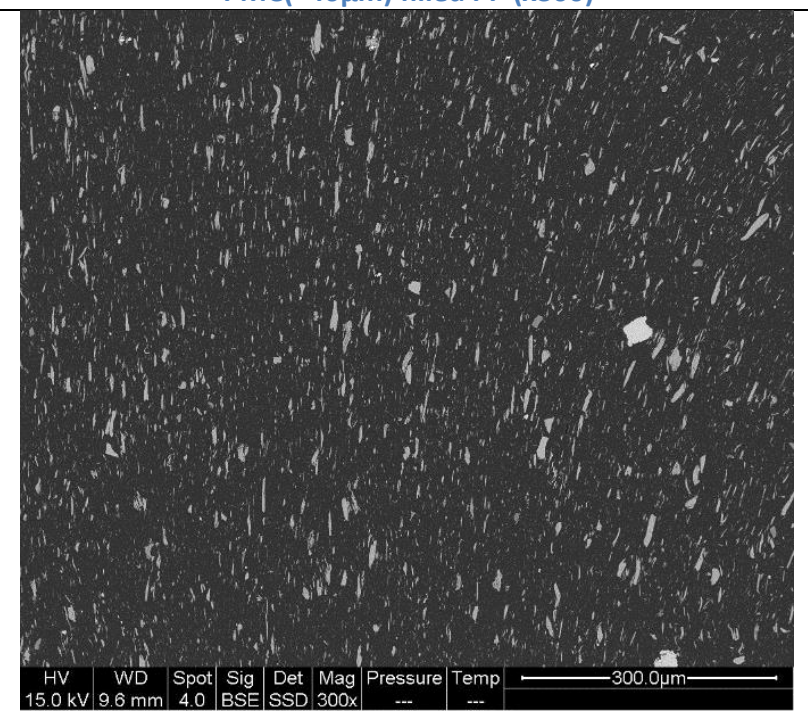

Figure 11: ESEM observation of polished cross section of $20 \%$ talc filled PP (x300)

While calcium carbonate particles are almost spherical in shape, or block like, PMC particles have a more complex shape, and are often slightly elongated. The polydispersity of PMC filler size distributions, which was quantified by laser diffraction PSD and previously described, can also be observed on these cross sections. No significant agglomeration of PMC filler is observed. On the other hand, PSD of $\mathrm{CaCO}_{3}$ seems much narrower, despite some aggregates or bigger particles. A different structure is observed for talc filled PP, related to the platelet shape of this filler. An anisotropic structure is obtained, with a high degree of orientation of talc platelet parallel to the injection flow (from top to bottom on Figure 11). The latter also corresponds to the orientation of solicitation in tensile test. Thus, most of talc particles/matrix interface is orientated parallel to the solicitation, while the perpendicular cross-section is very low. That provides a much higher frictional area between the talc filler and the matrix than between block-like (PMC and $\mathrm{CaCO}_{3}$ ) filler and PP during tensile and impact tests. 
An equivalent circular diameter was calculated from the images to compare with the size of the filler measured by laser diffraction before incorporation in the composites (Figure 12 and Figure 13). A good correlation is find for PMC fillers, especially for the fraction sieved at $40 \mu \mathrm{m}$ (LS data: $d_{50}=24 \mu \mathrm{m}$, d90 $=49 \mu \mathrm{m})$. A slightly smaller particle size is found for the PSD $<400 \mu \mathrm{m}$, especially in the upper fraction of the distribution ( $d_{50}=188 \mu \mathrm{m}$ by $L S$ ). This was expected as the measured areas are particular cross-section of particles, which is necessarily lower than their real total projected area (as approximatively measured by LS). The overall range of size of these distribution is however in agreement with the PSD measured by LS. That tends to shows that no significant PMC particles breakage occurs during the compounding and injection molding processes, and the initial PSD was apparently preserved in the composites. The median size diameter of $\mathrm{CaCO}_{3}$ is close to the one measured by $\mathrm{LS}\left(\mathrm{d}_{50}=6 \mu \mathrm{m}\right)$. However, the presence of aggregates and bigger particles is highlighted by this measurement. While they do not represent much of the distribution in number as seen on the previous picture, they constitute a high fraction when considering the surface distribution (between $20 \%$ and $30 \%$ ). Their sizes range from 30 and $70 \mu \mathrm{m}$, which is in the size range of the PMC PSD used in this study. The presence of aggregates might result from an insufficient mixing during the compounding, and to the low affinity of $\mathrm{CaCO}_{3}$ with the matrix. The PSD measured for talc differs quite significantly from the one measured by LS. Indeed, the particles measured by image analysis appears much smaller ( $d_{50}=17 \mu \mathrm{m}$ and $d_{90}=44 \mu \mathrm{m}$ by LS). This might be an artefact induced by the orientation of the particles, which are platelets like. On the analyzed images, only the thickness and the length dimension appears. In LS, the width, which can be in the order of size of the length, is also measured. The calculated equivalent circular diameter is therefore bigger.

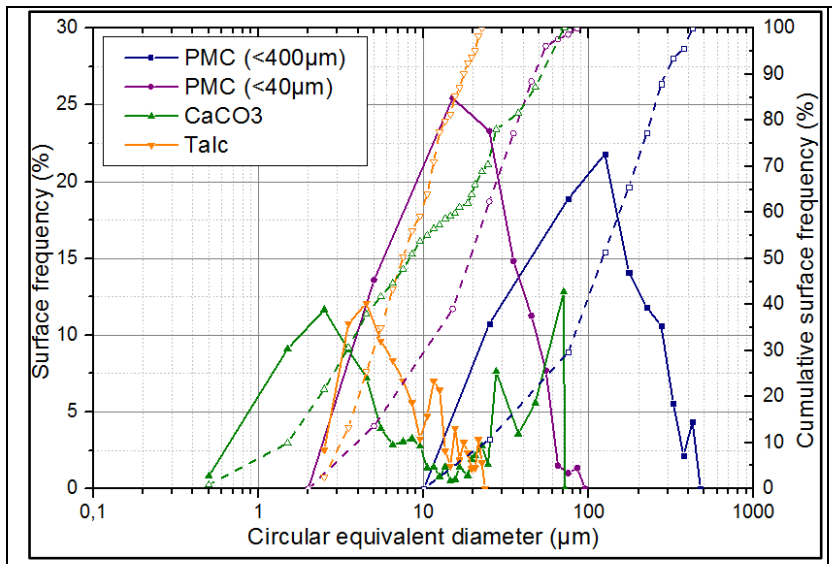

Figure 12 : Surface and cumulative surface frequency of fillers circular equivalent diameter measured by image analysis on composite polished section

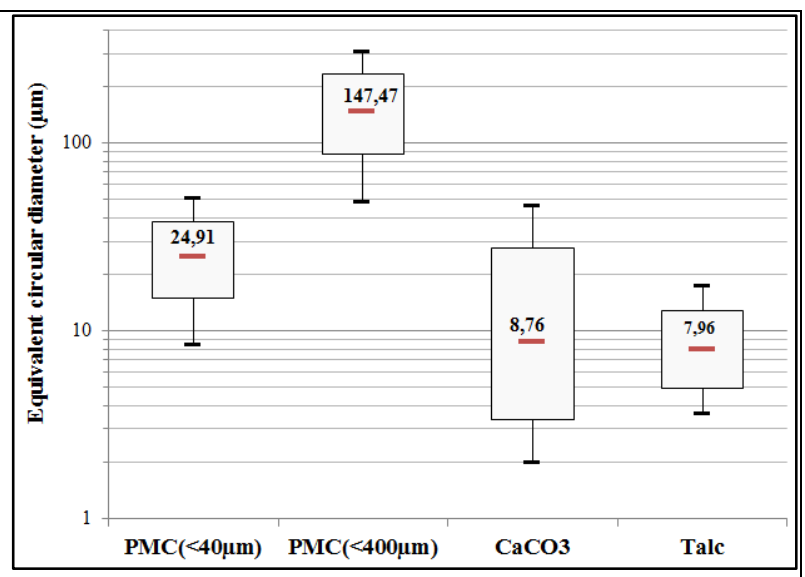

Figure 13 : Dimension of fillers measured by image analysis on composite polished section (central line : $d_{50}$, upper/lower box: $d_{75} / d_{25}$, upper/lower whisker: $d_{90} / d_{10}$ )

In term of morphology, these fillers differ in different ways. $\mathrm{PMC}$ and $\mathrm{CaCO}_{3}$ are block like, and talc is platelet like. This is reflected by their aspect ratio (Figure 14). For PMC filler, median aspect ratio of 1.59 and 1.68 are measured in composite (PS $<400 \mu \mathrm{m}$ and PS $<40 \mu \mathrm{m}$, respectively). This is higher than value measured by image analysis on PMC particles before incorporation in composite (for PSD < 40 $\mu \mathrm{m}$, a median value of 1.5 was obtained). However, a similar trend of increasing AR with decreasing particle size was already observed. The overall AR distributions of $\mathrm{PMC}$ particles are higher than $\mathrm{CaCO}_{3}$ one. The $\mathrm{PMC}$ 
particles are therefore slightly more elongated than $\mathrm{CaCO}_{3}$ and less spherical. Talc particles are much more elongated, with AR higher than 10.

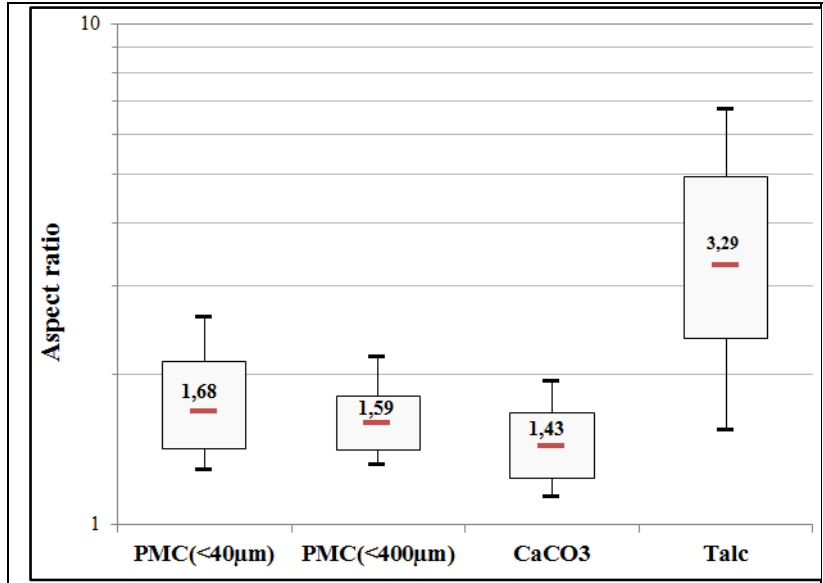

Figure 14 : Aspect ratio of different fillers measured by image analysis in composites cross-section

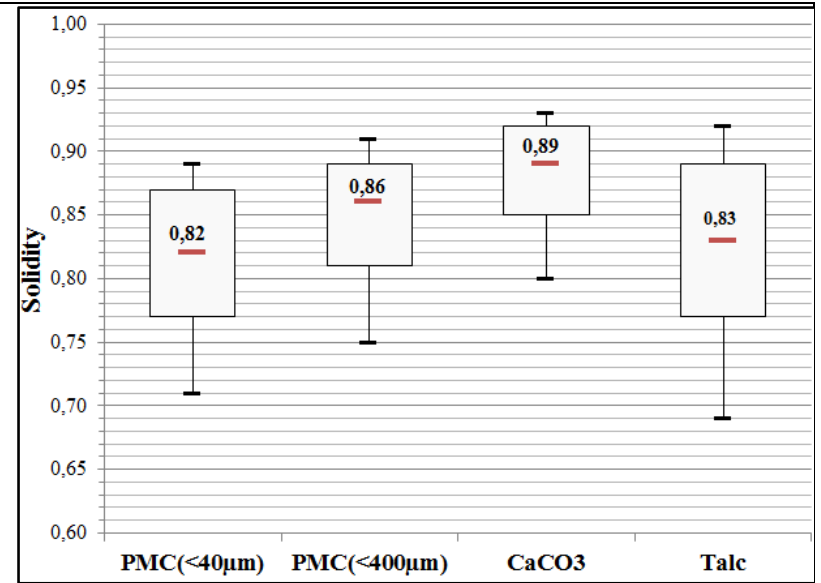

Figure 15 : Aspect ratio of different fillers measured by image analysis in composites cross-section

The irregularity of the shape of a particle is partially demonstrated by its solidity, which consider its convex area. While a circle or a cube has a solidity of 1 , the solidity decreases with increasing concavity in particle shape as well as surface irregularity. $\mathrm{CaCO}_{3}$ has the highest solidity of the considered fillers (Figure 15). It can be considered as the more spherical like, as previously observed on pictures. A decrease in solidity with decreasing particle size is observed for PMC. The median solidity of talc is slightly higher than the PMC $<40 \mu \mathrm{m}$, yet its dispersion is much higher. Low solidity for such elongated particles is mostly due to variation in particles thickness and bending of the lamellae.

Finally, the orientation of particles along the horizontal line was measured (Figure 16). While some minor preferred orientations are found for $\mathrm{PMC}$ and $\mathrm{CaCO} 3$, there is an overall good repartition in all direction. For talc, $67 \%$ of particles are oriented within a $20^{\circ}$ wide angle.

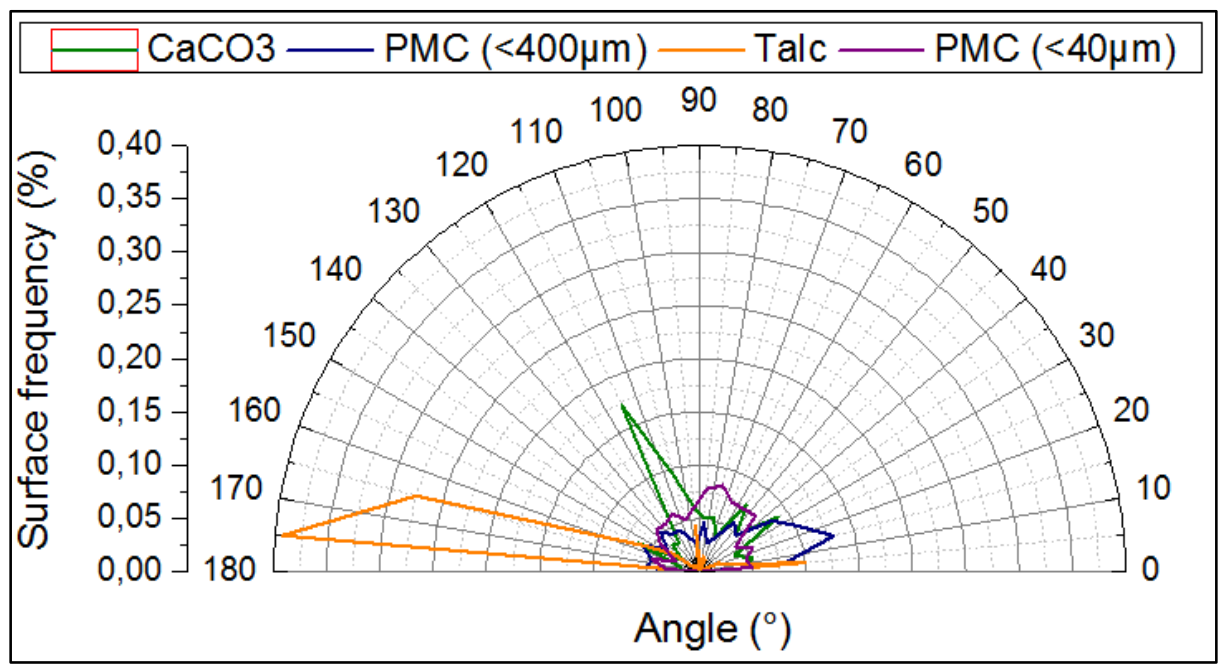

Figure 16 : Orientation of particles along the horizontal image line measured by image analysis 


\section{b. Mechanical properties: effect of particle size and comparison with other fillers}

The effect of particle size on tensile and impact strength was first investigated with the four top cutted filler distributions. An increase of the elastic modulus is observed with increasing loading percentage of the filler (Figure 17). This behavior is expected, as the phenolic molding compound has a higher elastic modulus $(7.8 \mathrm{GPa})$ than the PP matrix. Interestingly, unlike some proposed model for particle filled polymers, the relationship between modulus and volume fraction is almost linear.

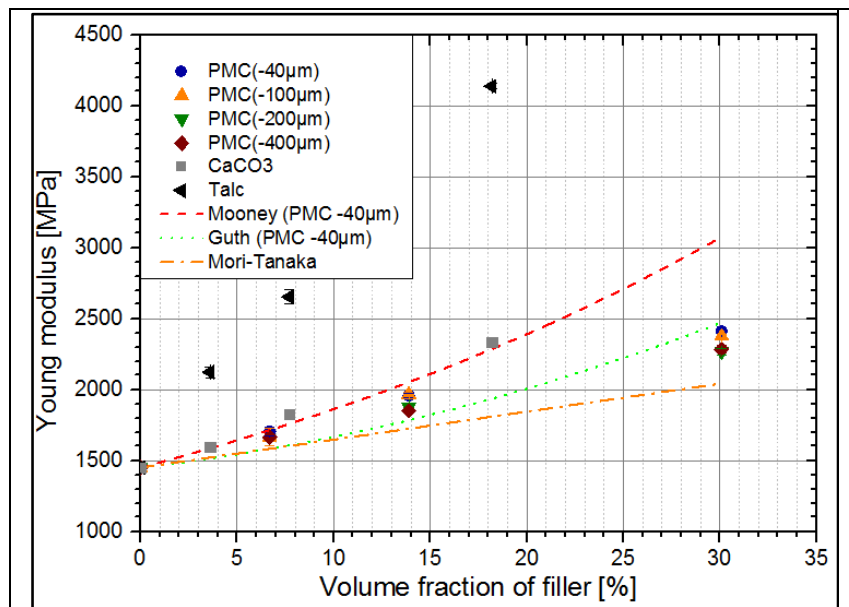

Figure 17: Young modulus of PMC, $\mathrm{CaCO} 3$ and talc filled PP for different loading percentage and particle size distribution of the filler

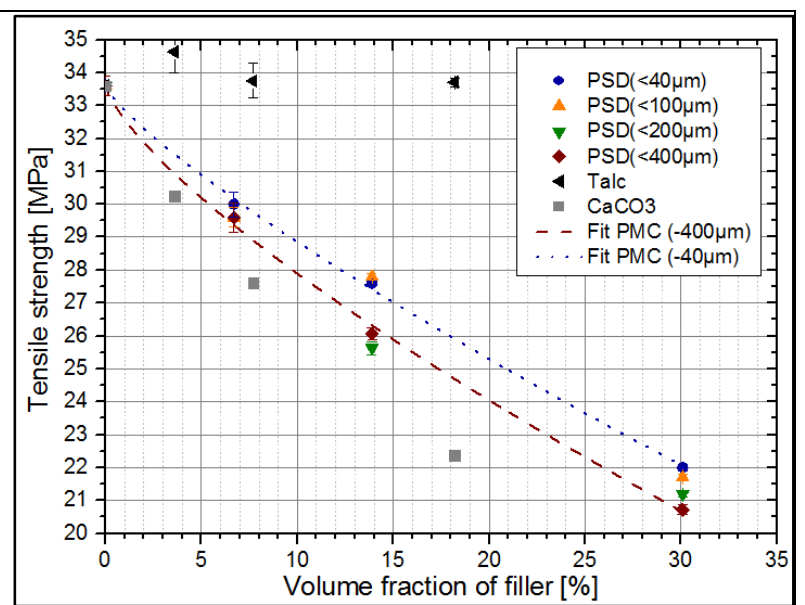

Figure 18: Tensile strength of PMC, $\mathrm{CaCO} 3$ and talc filled PP for different loading percentage and particle size distribution of the filler

While the same modulus is measured at $7 \%_{v}\left(10 \%_{w}\right)$ fraction for all filler PSD), the modulus at 14 $\%_{v}\left(20 \%_{w}\right)$ and $30 \%_{v}\left(40 \%_{w}\right)$ is slightly higher for the two smaller particle size distributions, i.e. $d_{50}=50 \mu m$ and $d_{50}=24 \mu \mathrm{m}$. At low volume fraction, a similar modulus is found for $\mathrm{CaCO}_{3}$ and PMC filled PP. This does not seem to hold at higher volume fraction, where $\mathrm{CaCO}_{3}$ filled PP has a higher modulus. Talc filled PP has a much higher modulus than $\mathrm{PMC}$ and $\mathrm{CaCO} 3$ filled PP. This can be explained by the high aspect ratio of talc and its orientated structure.

Most models fail to fit the observed increase of Young modulus of PMC filled PP. The Mooney model (Equation 2), well adapted for rigid mineral filler [21], is a good fit at low volume fraction (6.7\%v), but predicts higher modulus at high filler content. It fits well the measured modulus of $\mathrm{CaCO}_{3}$ filled PP. That shows that PMC can only be considered infinitely more rigid than the matrix at low volume fraction. The Mori-Tanaka model for spherical particles, which takes in account mechanical properties of filler and matrix, predicts a linear increase of modulus with volume fraction on the range considered. However, it is lower than the measured one. That might be explained by a higher modulus of the micronized PMC particles than bulk PMC, or by an effect of particles shape (not fully spherical). The best fit is obtained with Guth model (Equation 3) for non-spherical fillers [21], associated with a shape factor of 1.6. It is coherent with image analysis measurements. 


$$
\begin{array}{ll}
\text { Equation 2 } & \mathrm{E}_{\mathrm{C}}=\mathrm{E}_{\mathrm{M}} \exp \frac{2.5 V_{f}}{1-S V_{f}} \\
\text { Equation 3 } & \mathrm{E}_{\mathrm{C}}=\mathrm{E}_{\mathrm{M}}\left(1+0.67 \mathrm{p} \mathrm{V}_{\mathrm{f}}+1.62 \mathrm{p}^{2} \mathrm{~V}_{\mathrm{f}}{ }^{2}\right) \\
\text { Equation 4 } & \sigma_{\mathrm{C}}=\sigma_{\mathrm{M}}\left(1-\mathrm{a} \Phi^{\mathrm{b}}\right)
\end{array}
$$

With $E_{C}$ the composite modulus, $E_{M}$ the matrix modulus $\left(E_{M}=1450 \mathrm{MPa}\right)$, Фthe volume fraction of filler, $S$ the crowding factor, $p$ the shape factor, $\sigma_{C}$ and $\sigma_{M}$ the tensile strength of composite and matrix, a parameter related to the interfacial adhesion, and $b$ an adimensional parameter related to the mode of fracture.

The tensile strength decreases with increasing filler content for PMC filled PP (Figure 18), which is an expected behavior for particulate composites with a poor interfacial adhesion. As for the Young modulus, the tensile strength is almost the same at $7 \%$ fraction for all filler's PSD. For $14 \%_{v v}$, a higher tensile strength is measured for PSD with $d_{50}=50 \mu \mathrm{m}$ and $d_{50}=24 \mu \mathrm{m}$.

Power law have been used to fit the tensile strength behavior [22] (Equation 4). Two sets of parameters are obtained for the smaller and bigger PSD. Interestingly, the a parameter, which generally accounts for the adhesion between the filler and the matrix, is equal to 1.21 when there is no adhesion and decreases with increasing adhesion. It is found to be equal to 0.91 and 0.94 . That might indicate that some adhesion exists at the interface.

A decrease of tensile strength is also observed for $\mathrm{CaCO}_{3}$ filled PP. Lower values are measured for this system in comparison with $\mathrm{PMC}$ filled $\mathrm{PP}$, despite the much smaller size of $\mathrm{CaCO}_{3}$ particles. The reason for that is not dispersion (which is similar for both systems) or difference in matrix crystallinity, as previously shown. An obvious difference is the shape of the particles. While $\mathrm{CaCO}_{3}$ has smooth and convex shape, PMC particles has much more irregularity in their shape and concave parts, as demonstrated by image analysis. Such irregularities can provide mechanical interlocking for the matrix polymer at the microscopic scale. However, it can also lead to stress concentration inside and outside particles. While PMC with particles size inferior to $100 \mu \mathrm{m}$ and $40 \mu \mathrm{m}$ have a greater specific surface area than $\mathrm{CaCO}_{3}, \mathrm{PSD}$ $<200 \mu \mathrm{m}$ and $<400 \mu \mathrm{m}$ have a similar or inferior surface area than $\mathrm{CaCO}_{3}$, respectively. This parameter shouldn't be considered alone to explain those differences in tensile stress. The state of chemical or physical bonding between these fillers and the matrix is not known. Very little adhesion is supposed to exist in these systems, as the polypropylene matrix is an apolar polymer with low surface energy $\left(\gamma_{P P}=\right.$ $33.4 \mathrm{~mJ} / \mathrm{m}^{2}$ [27]). While calcium carbonate is highly polar $\left(\gamma_{\mathrm{CaCO} 3}^{p}=153.4 \mathrm{~mJ} / \mathrm{m}^{2}, \gamma_{\mathrm{CaCO} 3}=207.9 \mathrm{~mJ} / \mathrm{m}^{2}\right.$ [27]), the surface energy of PMC is closer to polypropylene's one, with a high dispersion component $\left(\gamma_{P M C}^{d}\right.$ $\left.=31.6 \mathrm{~mJ} / \mathrm{m}^{2}, \gamma_{P M C}=42.8 \mathrm{~mJ} / \mathrm{m}^{2}[32]\right)$.

No decrease of tensile strength is observed for talc filled PP and an increase is even measured for $4 \%$ loading rate. This type of behavior is generally observed for reinforcing filler with high aspect ratio. This can be explained by the high surface developed by aligned particles along the straining direction, which provides high adhesion surface with no debonding. 


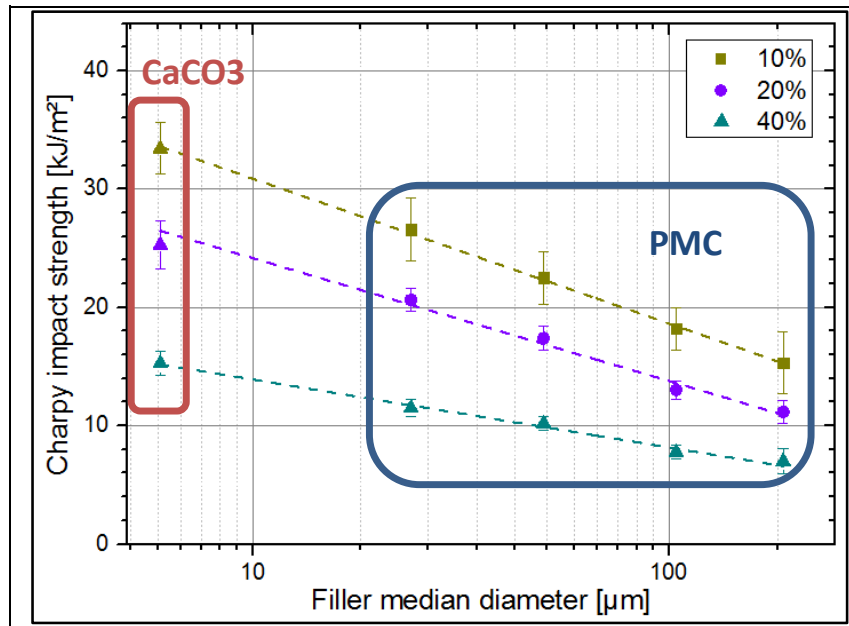

Figure 19 : Charpy impact strength of $\mathrm{CaCO}_{3}$ and $\mathrm{PMC}$ filled PP as a function of filler median diameter $\left(10,20\right.$ and $\left.40 \% \%_{\text {weight }}\right)$
Equation $5 \quad a_{c u}=a-b * \ln (d)$

\begin{tabular}{|l|c|c|}
\hline Loading & a & b \\
\hline $\mathbf{1 0 \%}$ & 43 & 5.3 \\
\hline $\mathbf{2 0} \%$ & 34 & 4.5 \\
\hline $\mathbf{4 0 \%}$ & 19.7 & 2.5 \\
\hline
\end{tabular}

Table 3 : Parameters used to fit impact strength versus filler median diameter curves

A different behavior is observed with Charpy impact test (Figure 19). First, the impact strength $\mathrm{a}_{\mathrm{cu}}$ of all composites is lower than for neat PP $\left(a_{c u}=92 \pm 12 \mathrm{~kJ} / \mathrm{m}^{2}\right)$. It decreases with loading content. However, the effect of particle size distribution is more obvious than in tensile test. It can be seen that the impact strength increases greatly as the particles size decreases. For example, at $10 \%_{w}$ loading, the impact strength of the composite filled with $d_{50}=24 \mu \mathrm{m}$ PMC particles is $74 \%$ higher than the one filled with $d_{50}$ $=188 \mu \mathrm{m}$ PMC particles. This effect is less pronounced at $40 \%_{\mathrm{w}}$ loading. Higher impact strengths are measured for $\mathrm{CaCO}_{3}$ filled PP. This can directly be linked with the smaller size of the particles.

It is possible to fit the impact strength as a function of filler size (Equation 5 and Table 3). Interestingly, the data obtained with $\mathrm{CaCO}_{3}$ filled PP are fitted with the same equation as PMC filled PP. That shows that the nature of a rigid filler (mineral or organic) or its properties doesn't influence much impact strength, the main factor being its size. Talc filled PP impact strength could not be properly plotted on this graphic, as no acceptable filler median diameter size can be defined for this platelet like filler. Higher impact strength is measured for this system $\left(43 \pm 2 \mathrm{~kJ} / \mathrm{m}^{2}\right.$ for $10 \%_{\mathrm{w}}, 28 \pm 3 \mathrm{~kJ} / \mathrm{m}^{2}$ for $20 \%_{\mathrm{w}}$ and 17.1 $\pm 0.5 \mathrm{~kJ} / \mathrm{m}^{2}$ for $40 \% \mathrm{w}$ ). Again, this may be related to the geometry of the filler.

Surface of rupture of samples after tensile test were observed with ESEM. Two areas can typically be sorted on these surfaces: a localized area with a high level of polymer matrix deformation, where cavitation occurred, probably initiating the breaking of the sample, and a larger area with little localized deformation, where the crack is propagated in a brittle way (Figure 20). 


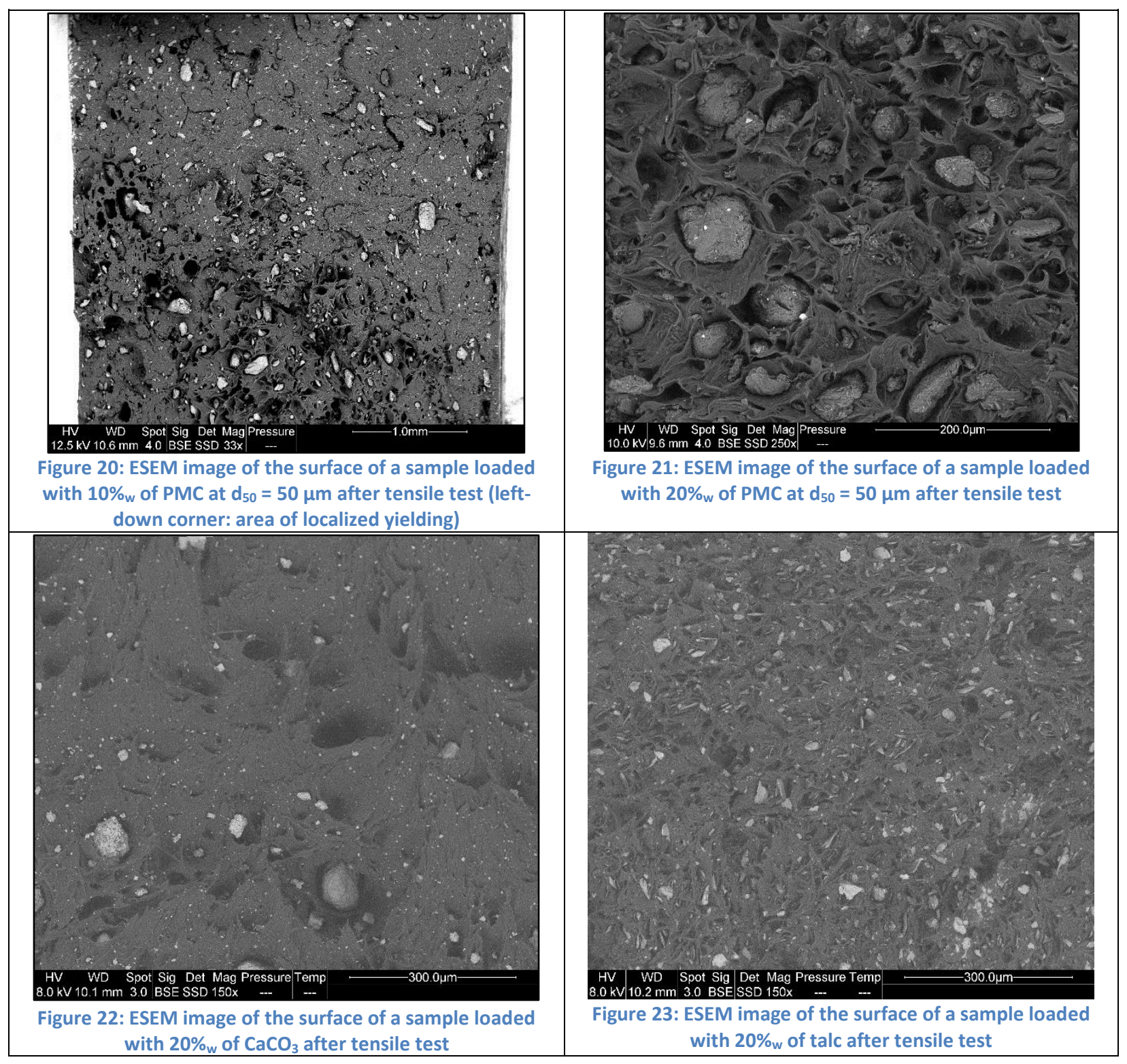

Obviously, very poor or no adhesion exists between the PP matrix and the phenolic fillers, leading to cavitation around the latter (Figure 21). This can be explained by the difference in polarity of these two polymers, the PP being an apolar plastic, and the phenolic resin being slightly more polar, because of phenolic hydroxyl for example. The same observation can be made for the minerals filled PP (Figure 22 and Figure 23).

The low adhesion could explain the loss of mechanical properties observed in these composites. In tensile test, the main phenomena is the decrease of the tensile strength, which is mostly dictated by the filler loading percentage, and is very little affected by the size of the filler. This decrease of the tensile strength in particulate composite is generally attributed to the decrease of the load bearing section due to the formation of cavity around the fillers, which is obviously observed. 
On the other hand, the effect of the size of the particles is obvious on impact test results. The main difference between these two mechanical tests, apart from the geometry, is the material straining rate. At low speed (tensile test), the effect of particles size seems to be hidden by the plasticity of the matrix, which accommodate the cavity created by the fillers through deformation mechanism. At higher straining rate (impact test), the ductility of the matrix is lowered, and its behavior probably becomes more brittle. Therefore it cannot accommodate the cavity created by the stress concentration around fillers.

\section{c. Effect of PSD dispersion and modes distribution}

While the PSD used in the first part of this study were quite broad, tailored PSD were produced in order to assess the specific effect of narrowness and number of mode of distributions on mechanical properties of PP filled with $20 \%$ PMC. A comparison is first made between two narrow distributions $(P M C(A)$ and $P M C(E))$ and a bimodal mixture of the two $(P M C(0.3 A+0.7 E))$. These two fractions and their ratio in the mixture were specifically chosen to achieve a powder with maximum compacity [33]. A microstructure obtained with this bimodal PSD is expected to have a greater interparticular distance in comparison with the one obtained with a narrow PSD. That might lead to a decrease in stress concentration in the matrix. While the composite filled with $\mathrm{PMC}(\mathrm{A})$ fraction has higher Charpy and tensile strength than PMC(E) filled PP (which is expected since $P M C(A)$ fraction median diameter is almost 10 ten time smaller than $\mathrm{PMC}(\mathrm{E})$ ), an intermediary strength value is obtained for the $\mathrm{PMC}(0.3 \mathrm{~A}+0.7 \mathrm{E})$ (Figure 24).

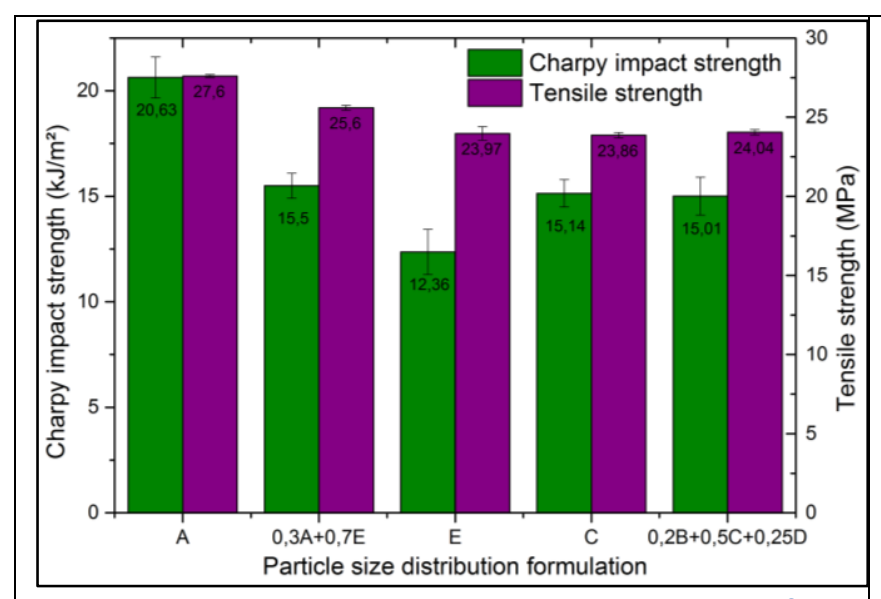

Figure 24 : Charpy impact strength and tensile strength of PP filled with $20 \%{ }_{w}$ of PMC with different PSDs

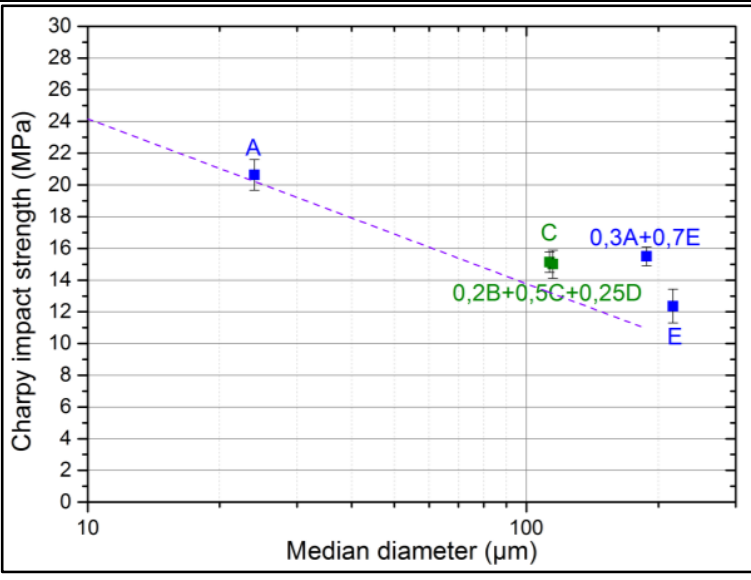

Figure 25 : Charpy impact strength of PP filled with $20 \%{ }_{w}$ of PMC with different PSDs; the dashed purple line correspond to the fitted model for $\mathbf{2 0} \%_{\mathrm{w}}$ loaded PP presented in Equation 5 and Table 3

A simple law of mixture of Charpy impact strength measured for $\mathrm{PP}+20 \% \mathrm{PMC}(\mathrm{A})$ and $P P+20 \% P M C(E)$ and weighted with corresponding weight fraction of powders $(0.3 A$ and $0.7 E)$ gives an impact strength of $14.8 \mathrm{~kJ} / \mathrm{m}^{2}$ for the mixture, which is lower than measured value. When considering the $d_{50}$ of the mixture, which is purely theoretical, it can be seen that the measured impact strength do not fit on the previously found model (Figure 25). A higher value is obtained. That shows that this simple equation 
cannot fully model the effect of complex particular size distribution on impact strength. More parameters have to be taken in account.

Similar impact and tensile strength are obtained for the narrow $(\mathrm{C})$ and the broad distribution $(0.25 \mathrm{~B}+0.5 \mathrm{C}+0.25 \mathrm{D})$. Whereas more large particles are present in the second distribution, the difference might not be significant enough to have a clear effect on mechanical properties of the composite. However, these two distributions can be compared with the PS<200 $\mu \mathrm{m}$, which has a $d_{50}$ of $104 \mu \mathrm{m}$, and which is even broader. Impact strength measured for this PSD are lower than for the two narrower PSD, which tend to shows that the presence of a significant fraction of large particles decrease the mechanical properties of the composite.

\section{d. Effect of coupling agents}

In order to improve the adhesion between the filler and the matrix, an adhesion promoter (PP-gMA) was added into the composite. It is a polypropylene grafted with anhydride maleic, a polar component. $3 \%$ by weight were added to composites with $10 \%_{w}$ and $20 \%_{w}$ of PMC and with two particle size distributions $(<40 \mu \mathrm{m}$ and $<100 \mu \mathrm{m})$. PP-g-MA addition leads to an increase of both tensile strength and Charpy impact strength (Figure 26 and Figure 27).

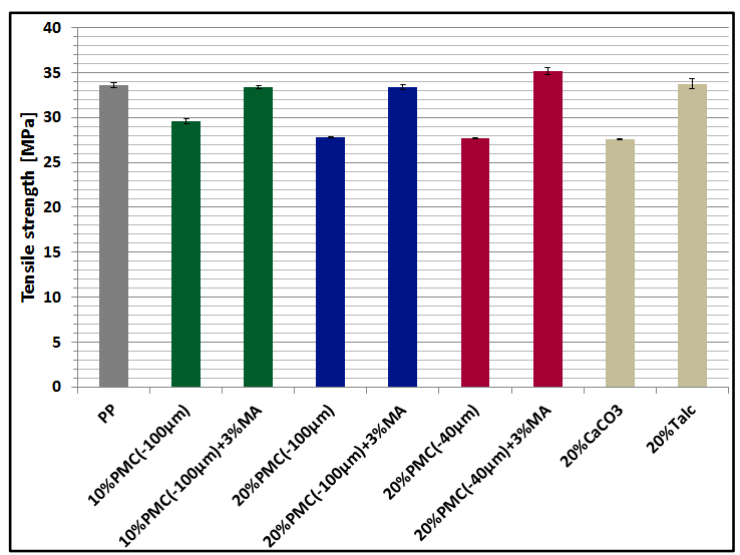

Figure 26 : Tensile strength with and without PP-g-MA

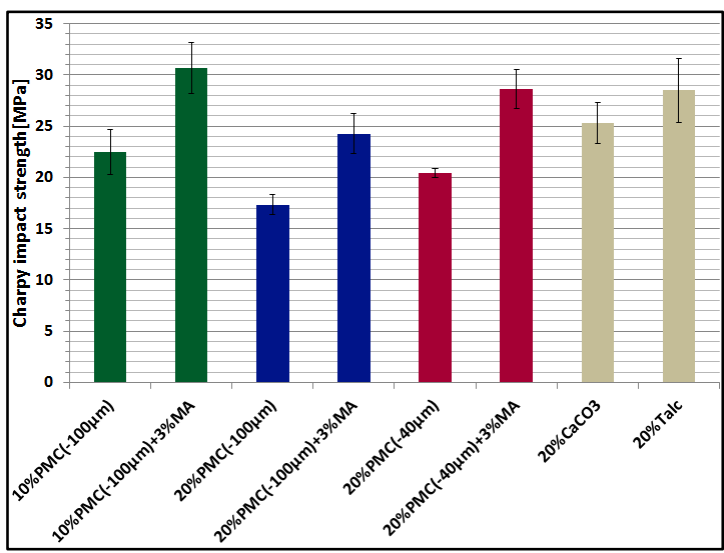

Figure 27 : Charpy impact strength with and without PP-gMA

In tensile mode, the modulus is not modified by the addition of PP-g-MA (for $10 \%{ }_{\mathrm{w}} \mathrm{PMC}(-100 \mu \mathrm{m})$, $E=1666 \pm 59 \mathrm{MPa}$ without PP-g-MA and $\mathrm{E}=1688 \pm 36 \mathrm{MPa}$ with; for $20 \%{ }_{\mathrm{w}} \mathrm{PMC}(-100 \mu \mathrm{m}), \mathrm{E}=1966 \pm 15 \mathrm{MPa}$ without PP-g-MA and $\mathrm{E}=1897 \pm 38 \mathrm{MPa}$ with). However, it increases the tensile strength almost to the same value (or higher) as the PP for all formulations. Impact strength also increases when PP-g-MA is added.

The PMC filled composites were compared with $\mathrm{CaCO}_{3}$ and talc filled composites. With no PP-gMA added, the tensile properties (modulus and tensile strength) are very similar to $\mathrm{a} \mathrm{CaCO}_{3}$ filler PP. The PMC therefor plays an inert filler role. When PP-g-MA is added, similar tensile and impact properties as Talc filled PP are observed. In this case, a semi-reinforcing role is ensured by the PMC.

ESEM observations of fractured surface after tensile test were made in order to verify the effect of PP-g-MA on adhesion between filler and matrix (Figure 28 and Figure 29). 


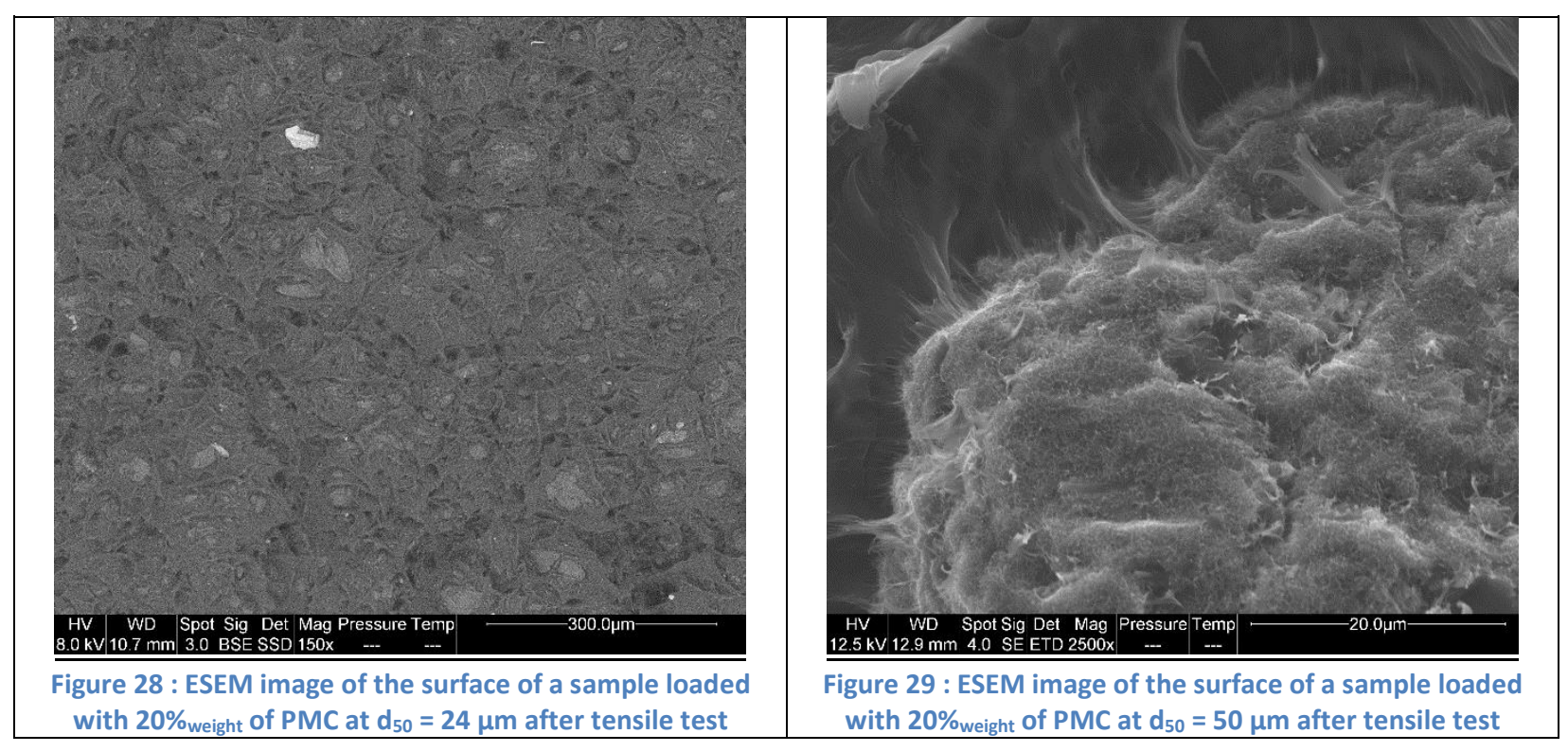

In the localized yield zone, while some limited cavitation can be seen around particles, no debonding can be observed around many particles. Some bonding in a fibrillar form between the PMC and the matrix can be observed around particles. Moreover, polymers filaments are still attached on the surface of the particles after debonding, suggesting that a cohesive zone exists around particles. PP-g-MA effectively increased the adhesion between the filler and the matrix.

While PP-g-MA obviously migrated at the interface between the filler and the matrix during the compounding process, it might also still exists in a dispersed state in the matrix. Such an additive dispersed in the matrix might modify its mechanical properties, thus the mechanical properties of the matrix. In order to assess this affect, a compound made of PP $+3 \%$ PP-g-MA was prepared and mechanically tested in tensile mode (Figure 30).

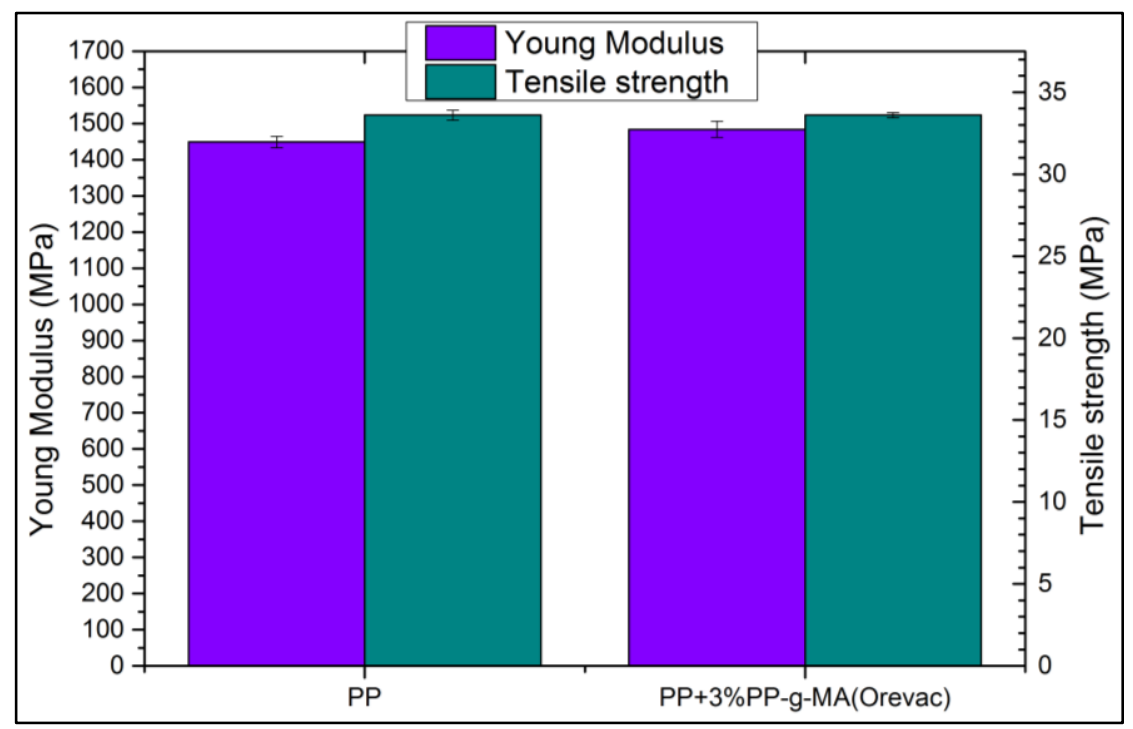

Figure 30 : Tensile properties of PP and PP+3\%PP-g-MA (Orevac) 
Similar modulus and tensile strength are measured for neat PP and PP with PP-g-MA. Therefore, the potential presence of PP-g-MA as a dispersed component in PP/PP-g-MA/PMC composite might not modify their properties.

\section{Conclusion}

The effect of PMC waste powder on polypropylene mechanical and microstructural properties has been studied in this work. It appears that it behaves as regular particulate filler. With increasing loading rate, an increase in composites modulus is measured, associated with a decrease in tensile and impact strength. Tensile properties of PMC filled PP can be reasonably predicted with standard models generally used to describe properties of minerals filled polymers. At low volume fraction, a similar modulus in found for $\mathrm{CaCO}_{3}$ and $\mathrm{PMC}$ composites. At higher fraction, $\mathrm{CaCO}_{3}$ composites have a higher modulus. This might be explained by the higher rigidity of the mineral filler. For larger PSD of PMC filler and high volume fraction, a decrease of crystallinity is also measured, which might explain the slightly lower modulus in comparison with smaller PSD. A decrease of tensile strength is observed with increasing volume fraction of filler, which is expected for filler with little adhesion with the matrix. However, higher tensile strength obtained for the PMC filler than for $\mathrm{CaCO}_{3}$, which can be explained by better physical adhesion of the former particles.

A decrease of impact strength is observed with increasing volume fraction and size of PMC particles. It is possible to fit the impact strength of composite as a function of the median size diameter of the filler with a logarithmic function. The data for $\mathrm{CaCO}_{3}$ filled PP can also be fitted with this model by taking in account the size of this filler, showing that the filler nature and properties doesn't influence much the impact strength when there is little adhesion. However, the exact PSD has to be taken in account to develop a more precise model for impact strength prediction.

The addition of PP-g-MA effectively increased the interfacial adhesion between PMC and PP as shown by ESEM images. This led to an increase in both tensile and impact strength. Similar or higher values than talc filled PP are obtained, showing that PMC can be used as semireinforcing filler. This work shows that this thermoset material can be recycled as functional filler in a thermoplastic matrix, improving its mechanical properties in a similar way as conventional semi-reinforcing filler such as talc. This recycling process allows substitution thus saving of natural resources, while limiting the environmental impact of landfilling.

\section{References}


phenolic resin containing waste streams to sequentially recover momers and chemicals," WO 92/21639, 1992.

[2] S. J. Pickering, "Recycling technologies for thermoset composite materials-current status," Compos. Part A Appl. Sci. Manuf., vol. 37, no. 8, pp. 1206-1215, Aug. 2006.

[3] M. Suzuki, T. Ueno, H. Onishi, and Y. Ono, "Recycling of cured phenolic resin and a product such as a vacuum thermal insulator obtained thereby," EP 0940239 A1, 1999.

[4] Y. Yang, R. Boom, B. Irion, D. J. van Heerden, P. Kuiper, and H. de Wit, "Recycling of composite materials," Chem. Eng. Process. Process Intensif., vol. 51, pp. 53-68, Jan. 2012.

[5] Y. Suzuki, H. Tagaya, T. Asou, J. Kadokawa, and K. Chiba, "Decomposition of Prepolymers and Molding Materials of Phenol Resin in Subcritical and Supercritical Water under an Ar Atmosphere," Ind. Eng. Chem. ..., vol. 38, no. 4, pp. 1391-1395, 1999.

[6] H. Tagaya, Y. Suzuki, T. Asou, J. Kadokawa, and K. Chiba, "Reaction of Model Compounds of Phenol Resin and Molding Materials of Phenol Resin in Supercritical Water for Chemical Recycling of Polymer Waste," Chem. Lett., vol. 27, no. 9, pp. 937-938, 1998.

[7] T. Sugeno and H. Tagaya, "The effects of solvents on the chemical decomposition of foamed phenol resin in high-temperature conditions," J. Mater. Cycles Waste Manag., vol. 17, pp. 453458, 2015.

[8] Y. Sato, Y. Kodera, and T. Kamo, "Effect of Solvents on the Liquid-Phase Cracking of Thermosetting Resins," Energy Fuels, vol. 12, no. 2, pp. 364-368, 1999.

[9] Y. Sato, Y. Kodera, J. Goto, and Y. Matsui, "Effect of polystyrene addition on the monomer recycling of phenol novolac," Polym. Degrad. Stab., vol. 78, no. 2, pp. 315-322, 2002.

[10] D. Braun, W. Von Gentzkow, and a. P. Rudolf, "Hydrogenolytic degradation of thermosets," Polym. Degrad. Stab., vol. 74, no. 1, pp. 25-32, 2001.

[11] J. Goto, "Chemical recycle of thermosetting resin in supercritical water." .

[12] J. Ozaki, S. Djaja, and A. Oya, "Chemical recycling of phenol resin by supercritical methanol," Ind. Eng. Chem. ..., vol. 39, no. 2, pp. 245-249, 2000.

[13] C. E. Bream and P. R. Hornsby, "Comminuted thermoset recyclate as a reinforcing Part I Characterisation of recyclate feedstocks," vol. 6, pp. 2965-2975, 2001.

[14] C. E. Bream and P. R. Hornsby, "Comminuted thermoset recyclate as a reinforcing filler for thermoplastics - Part II : Structure-property effects in polypropylene compositions," J. Mater. Sci., vol. 36, pp. 2977-2990, 2001.

[15] C. Bream and P. Hornsby, "Structure development in thermoset recyclate-filled polypropylene composites," Polym. Compos., vol. 21, no. 3, pp. 417-435, 2000.

[16] A. P. Cavalcante and L. B. Canto, "Use of Industrial Waste Based on Phenolic Resin as Filler for Polypropylene," Polimeros, vol. 22, no. 3, pp. 245-252, 2012.

[17] Dilhan M. Kalyon, M. Hallouch, and N. Fares, "Recycling of thermosets as fillers," ANTEC'84, pp. 640-642, 1984.

[18] M. Gröning, H. Eriksson, M. Hakkarainen, and A. C. Albertsson, "Phenolic prepreg waste as functional filler with antioxidant effect in polypropylene and polyamide-6," Polym. Degrad. Stab., vol. 91, no. 8, pp. 1815-1823, Aug. 2006.

[19] L. Cui, S. Wang, Y. Zhang, and Y. Zhang, "Dynamically Cured Polypropylene / Novolac Blends Compatibilized with Maleic Anhydride- g -Polypropylene," 2007.

[20] W.-Y. Chiang, W.-C. Wu, and B. PUKANSZKY, "MODIFICATION OF POLYPROPYLENE, BLENDING WITH RESOLE TYPE PHENOL-FORMALDEHYDE RESINS," Eur. Polym. J., vol. 30, no. 5, pp. 573-580, 1994.

[21] S. Ahmed and R. Jones, "A review of particulate reinforcement theories for polymer composites," J. Mater. Sci., vol. 25, pp. 4933-4942, 1990.

[22] D. M. Bigg, "Mechanical properties of particulate filled polymers," Polym. Compos., vol. 8, no. 2, 
pp. 115-122, Apr. 1987.

[23] B. Bitsch, "Amélioration des thermoplastiques - Rôle du compoundeur," Tech. l'ingénieur, 2003.

[24] S.-Y. Fu, X.-Q. Feng, B. Lauke, and Y.-W. Mai, "Effects of particle size, particle/matrix interface adhesion and particle loading on mechanical properties of particulate-polymer composites," Compos. Part B Eng., vol. 39, no. 6, pp. 933-961, Sep. 2008.

[25] J. Z. Liang and R. K. Y. Li, "Prediction of tensile yield strength of rigid inorganic particulate filled thermoplastic composites," J. Mater. Process. Technol., vol. 83, no. 1-3, pp. 127-130, Nov. 1998.

[26] J. Z. Liang, "Toughening and reinforcing in rigid inorganic particulate filled poly(propylene): A review," J. Appl. Polym. Sci., vol. 83, pp. 1547-1555, 2002.

[27] J. Móczó and B. Pukánszky, "Polymer micro and nanocomposites: Structure, interactions, properties," J. Ind. Eng. Chem., vol. 14, no. 5, pp. 535-563, Sep. 2008.

[28] M. Chevalier, "Phénoplastes ou phénols-formols," Tech. l'ingénieur, 1991.

[29] L. Sperling, Introduction to physical polymer Science. 4th ed. John Wiley \& Sons In, 2006.

[30] J. Weon and H. Sue, "Mechanical properties of talc- and CaCO 3 -reinforced high-crystallinity polypropylene composites," J. Mater. Sci., vol. 41, no. 8, pp. 2291-2300, 2006.

[31] P. M. McGenity, J. J. Hooper, C. D. Paynter, A. M. Riley, C. Nutbeem, N. J. Elton, and J. M. Adams, "Nucleation and crystallization of polypropylene by mineral fillers: relationship to impact strength," Polymer (Guildf)., vol. 33, no. 24, pp. 5215-5224, 1992.

[32] Y. Matsushita, S. Wada, K. Fukushima, and S. Yasuda, "Surface characteristics of phenolformaldehyde-lignin resin determined by contact angle measurement and inverse gas chromatography," Ind. Crops Prod., vol. 23, no. 2, pp. 115-121, Mar. 2006.

[33] S. M. K. Rassouly, "The packing density of 'perfect' binary mixtures," Powder Technol., vol. 103, no. 2, pp. 145-150, Jul. 1999. 